\title{
Effects of different strength training methods on dynamic balance in basketball players
}

\author{
Adnan Ersoy ${ }^{1 a}$, Oğuzhan Yüksel ${ }^{1}$, Mustafa Erzeybek ${ }^{1}$, Halit Harmanc1 ${ }^{1}$, and M. Barış \\ Karavelioğlu ${ }^{1}$ \\ ${ }^{1}$ School of Physical Education and Sport, Dumlupınar University, Kütahya, Turkey
}

\begin{abstract}
You should leave $8 \mathrm{~mm}$ of space above the abstract and $10 \mathrm{~mm}$ after the abstract. The heading Abstract should be typed in bold 9-point Arial. The body of the abstract should be typed in normal 9-point Times in a single paragraph, immediately following the heading. The text should be set to 1 line spacing. The abstract should be centred across the page, indented $17 \mathrm{~mm}$ from the left and right page margins and justified. Keywords: Strength training methods, dynamic balance, basketball players.
\end{abstract}

\section{Introduction}

Muscle power required for get high sport performance levels in basketball [16]. At the same time, balance and speed are important factors for the success of basketball players [3]. The good balance in basketball provides controlled body for players, minimize their errors, protect against the drop when change their directions, quick moves and effective technical skills [19]. Not only preseason but also season training plan contain some coordinative and balance workout for devolop biomotor abilities in basketball. Some training programs provide to increase muscular function and neuromuscular control at the same time develops balance and joint proprioception [2]. Neuromuscular training protocols include plyometric, biomechanics and technique, power, balance and core stability for provide neuromuscular changes and protect against possible injuries $[13,22]$. Functional training is defined as an exercise process that best teaches that an athlete manages body weight on all planes of motion. It's make a movement economically [9]. Hypertrophy and general power exercises can improve performance but specific exercise programs must be choice for the optimal transfer of the training [34]. Functional exercise programs are effective in preventing the recurrence of painless function and injuries of athletes. In general, four factors are targeted. A) Exercises to improve the stability of the spine during movement B) Works to improve equilibrium and proprioception. C) Win back to range of motion in a muscle. D) Exercises for functional strength development [33] Variable resistance has gained popularity in the last decade. Use of chain and elastic bands in resistance exercise cause the change speed

\footnotetext{
${ }^{a}$ Corresponding author: adnan.ersoy@dpu.edu.tr
} 
and strength directions [29] Behm and Anderson examined the resistance training and instability effect may have a role force output, body and extremity muscle activation, cocontractions, coordination and rehabilitation applications [8] Strength exercises using the Bandbell earthquake bar are preferred to increase the balance and joint proprioception interaction. All functions to a normal classic bar it can be by bandbell earthquake bar. Strength training forms can be applied to the end portions of the 5-pound bamboo stick with weights placed with elastic bands [4] Anderson, Sforzo and Sigg tried to determine different power and power adaptations according to free weight resistance training, elastic resistance and free-weight resistance training on 44 college-aged athletes [1]. The results of this study indicate that the athletes applying combined elastic and free-weight resistance alone have greater strength development in the upper and lower extremity than the traditional free weight [1]. Hess et al. They found that there was a strong relationship between lower extremity strength and postural control ability [12] Paterno et al. [26] and Young et al. [34] strength training results in a significant increase in static and dynamic stability. In this study, it was aimed to investigate the dynamic balance effect of the strength training program which is formed by using traditional bar with bandbell earthquake bar as functional training.

\section{Materials and methods}

33 male basketball players (13 control, 10 classic strength training, 10 earthquake strength bar training) whom at least 18 years old participated voluntarily in the study. The participants mean of body height measured $(n=33) 187,9 \pm 9,82 \mathrm{~cm}$, mean of body weight measured 84,5 $\pm 10,7 \mathrm{~kg}$, mean of age recorded 21,7 $\pm 1,62$ years. One day before the measurements the participants were informed about the test and information was provided that there was no drawbacks to the health of the tests.

The body weights of the athletes have been measured when they were standing upright in the standard sports clothing (shorts and tank-top) bare foot on the scale (Tanita TBF 401 A Japan) with \pm 100 gr error. Length: The length has been measured using a Holtain Limited branded tool, when the participants were standing upright bare foot with minimum clothing, the soles being adjacent, heads being high and eyes looking straight ahead. The sliding caliper on the scale has been adjusted as to be right on the top of the participant's head, read and recorded. Participants of experiment group divided into two group and traditional strength training (Figure 2) was applied for eight weeks. While participants who in-group one was practice with normal weight bar in their training program, participants who in-group two was practice with bandbell earthquake bar in their training program.

Bandbell Earthquake Bar: Bandbell earthquake bar made from Bamboo wood. Bar's weight is $2,5 \mathrm{~kg}$, lenght $2,03 \mathrm{~cm}$, diameter $3,81 \mathrm{~cm}$, maximal carrying capacity $150 \mathrm{~kg}$ and distance between collars $137 \mathrm{~cm}$. Bandbell earthquake bar actually made from hardened ash wood with a composite resin center section scientifically engineered for maximum flexibility and durability. There are two channels for the wood parts to prevent super loop bands from slipping. Bar was designed oscillating kinetic energy principle. Weight plates with 4 red flexible band (cherry super loop medium sanctband) was placed bandbell earthquake bar (figure1)(http://www.fitnessshop.com.tr/urunler/fonksiyonel-egzersizkipmanlari/bandbell-earthquake-bar/\#aciklama) ( http://www.ardsport.com/?uid=176). 


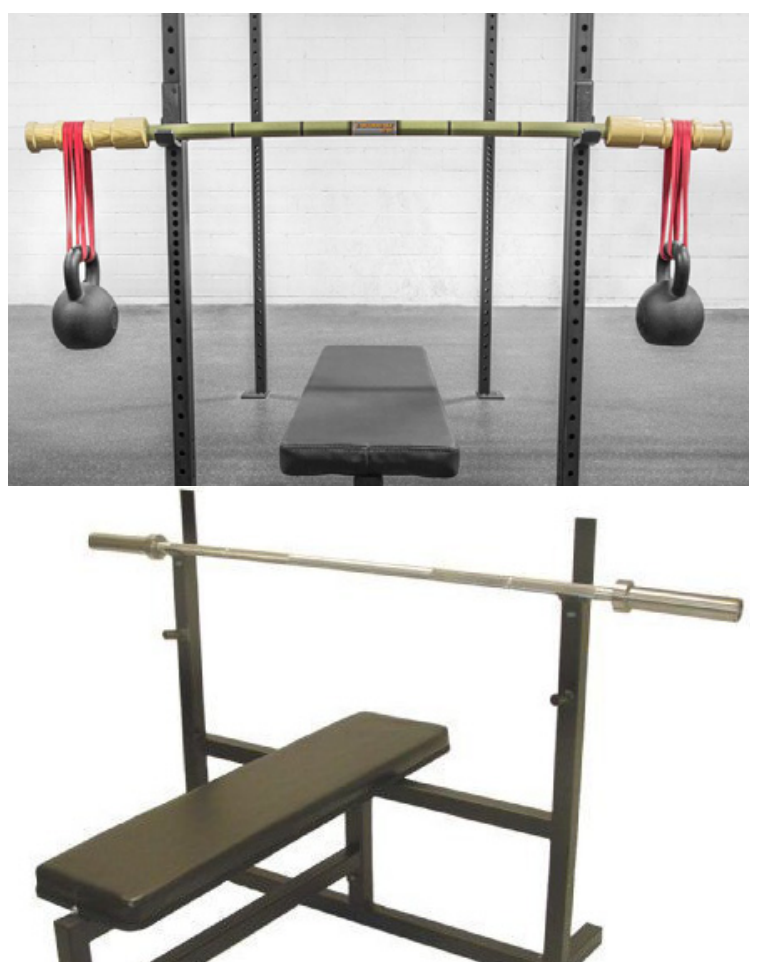

Fig. 1. Bandbell Earthquake Bar and Normal Traditional Bar

Dynamic Balance: When measuring the stability level, the authors used a Libra seesaw balancing board manufactured by EasyTech (length: $43 \mathrm{~cm}$; width: $42 \mathrm{~cm}$; height: $65 \mathrm{~cm}$ ). The testing stand was comprised of two components: a balance board with USB interface, controlled by EasyTech 2.2001-2.0 computer software developed by the device's manufacturer, and a computer set. The stabilometer allowed for measurements in the frontal plane (FP) and sagittal plane (SP) within the range of angular inclination of $\pm 15^{\circ}$, with a maximum measurement error of $0.1^{\circ}$. Electrical signals obtained from a potentiometer in the measurement circuit were converted by means of an analog-to-digital converter card. EasyTech 2.2001-2.0 software interface compute 4 parameters of balance (Figure 4)

Total Area (TA) - the area contained between the line of a movement pathway recorded for a subject and the model line.External Area (EA) - the area contained between the line of a movement path recorded for a subject and the line of a pre-set level of difficulty.

External Time (ET) - total time when a subject remains outside the area of a pre-set level of difficulty.

Recovery Time (RT) - the longest individual time when the subject remained outside the area of a pre-set level of difficulty [31].

Libra hardness level adjustable from the board's surface $(10 \mathrm{~cm}, 25 \mathrm{~cm}$ ve $40 \mathrm{~cm})$. The level of our test was $10 \mathrm{~cm}$. At the beginning every participants put each foot center (transvers plane). Three trial were given and the best one was recorded. Libra balance plate was placed a box $(50 \mathrm{~cm} \times 50 \mathrm{~cm} \times 50 \mathrm{~cm})$ for the participants sit (Feet and hands without touching any place). When sitting the box feet and hands without touching any place, attempted to maintain the balance line on the Libra seesaw balancing board with the rightleft lateral flexion of the torso. Balance scores were recorded at the end of 3 trials (Figure 3) [32]. 


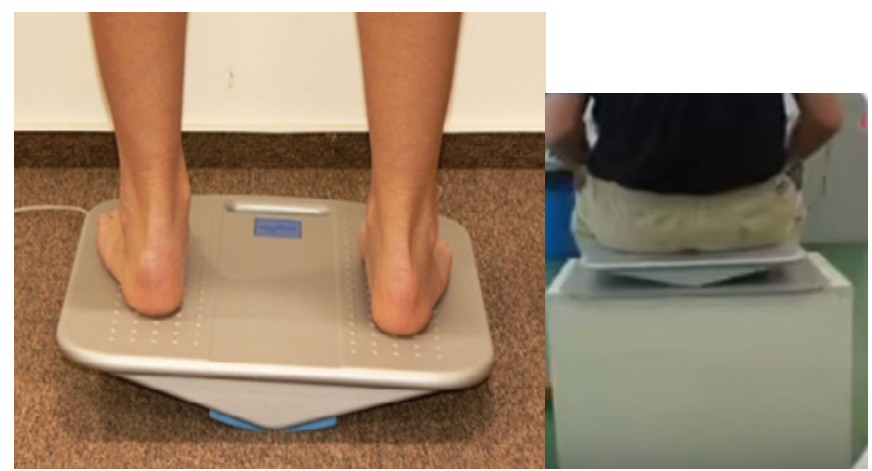

Fig. 3. Double Leg Transvers and Body Lateral Position

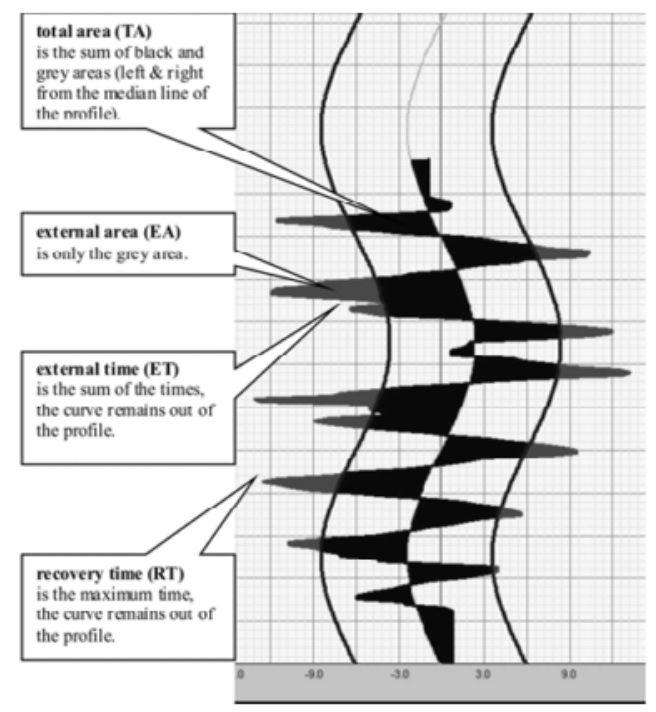

Fig. 4. EasyTech Libra Screenshot [31].

\subsection{Training program}

One repeat maximum of participants between $60-80 \%, 3$ set, and $8-10$ repeat was chose both strength training group. When they reach the $80 \%$ density, repetition was drop 8 and set was increased 4. Participants were practice half squat, military press, calf raise and bench press for eight weeks, three day in a week. Load densities for the first three weeks are one, $60 \%$ of maximum repetition, $4-6.70 \%$ between weeks and $80 \%$ over the last two weeks. In the bandbell earthquake bar group, the set numbers were modified as 5 when reaching $145-150 \mathrm{~kg}$ at $80 \%$ load at half squat station. Bandbell earthquake bar's capacity is limited to $150 \mathrm{~kg}$ by the manufacturer [1].

Dynamic balance (Libra) values from participants; Two-way repeated measures of ANOVA were performed by determining the balance values at the lateral position and the transverse position of the two feet. 


\section{Results}

Three different group (Classic Strength Training Group, Bandbell Earthquake Bar Group and Control Group) Body Balance at Lateral Position and Double Foot Transverse Balance first test and last test values shown on Table 1. According to results, there was a significant difference between Body Balance at Lateral Position $(\mathrm{F}=24.86, \mathrm{p}<0.05)$ and Double Foot Transverse Balance $(\mathrm{F}=14.571, \mathrm{p}<0.05)$ scores.

Table 1. Athletes Balance Values ANOVA Results

\begin{tabular}{|c|c|c|c|c|}
\hline Variables & & $\begin{array}{l}\text { Pre-test } \\
\text { Mean } \pm \text { SD }\end{array}$ & $\begin{array}{l}\text { Post-test } \\
\text { Mean } \pm \text { SD }\end{array}$ & Group X Time F \\
\hline \multirow{3}{*}{$\begin{array}{l}\text { Body } \\
\text { Balance at } \\
\text { Lateral } \\
\text { Position }\end{array}$} & $\begin{array}{l}\text { Classic Strength } \\
\text { Training Group }\end{array}$ & $37.23 \pm 5.49$ & $26.45 \pm 6.52$ & \multirow{3}{*}{$24.86^{*}$} \\
\hline & $\begin{array}{l}\text { Bandbell } \\
\text { Earthquake Bar } \\
\text { Group } \\
\end{array}$ & $41.66 \pm 5,24$ & $31.49 \pm 8.16$ & \\
\hline & Control Group & $39.38 \pm 5.33$ & $37.74 \pm 5.64$ & \\
\hline \multirow{3}{*}{$\begin{array}{l}\text { Double } \\
\text { Foot } \\
\text { Transvers } \\
\text { e Balance }\end{array}$} & $\begin{array}{l}\text { Classic Strength } \\
\text { Training Group }\end{array}$ & $33.85 \pm 4.34$ & $27.94 \pm 4.38$ & \multirow{3}{*}{$14.571^{*}$} \\
\hline & $\begin{array}{l}\text { Bandbell } \\
\text { Earthquake Bar } \\
\text { Group }\end{array}$ & $34.26 \pm 2.99$ & $29.32 \pm 3.52$ & \\
\hline & Control Group & $28.12 \pm 3.36$ & $27.6 \pm 3.64$ & \\
\hline
\end{tabular}

\section{Discussion and conclusion}

The results of the study showed significant reductions in equilibrium values in participants' practice of traditional bar and bandbell Earthquake bar strength training. The decline in equilibrium scores indicates that equilibrium is affected positively. It was seen that muscle activation produced by unbalanced loads at reduced loads compared to conventional equipment is higher in the literature McBride et al., [20], Park \& Yoo, [25]; Pinto et al., [27]. Azar's assessment of the effect of the Bandbell Earthquake Bar on the shoulder muscle activation of the traditional bar suggests that the quake bar increased muscle activation more than the traditional bar [4]. While the conventional bench press is generating linear force with a fixed line the bench press performs action with a high degree of freedom, which the participant's movement direction cannot easily predict by Bandbell Earthquake Bar [8, 11, 15, 23]. Ostrowski et al. defined all hanging load with elastic bands fast and securely press to a flexible bar [24].

In bandbell earthquake bar excessive muscular activation in strength training depending interaction is expected to increase load density and repetition. During the eight weeks training process it is likely that there will be an increase in strength values depending on resistance. It is thought that the change in participants' equilibrium values depends on the resistance gain of the lower extremity and upper extremity muscles. Furthermore, it was expected that the muscular activation of the Bandbell Earthquake bar would be more effective in balance values. When balance scores are taken into account the effect of the Bandbell Earthquake bar appears to be in parallel with the results of training with the traditional bar. Muehlbauer et al. in their study of 27 healthy adults, they found no significant relationship between dynamic-static equilibrium and isometric strength upper, lower and body strength. (Static-dynamic balance and isometric strength; $r=+0.041$ to 
$+0.0387, \mathrm{p}>0.05)$ [21]. Lee and Park's study indicates that increase in lower extremity strength positively affects balance in older adults aged 65-82 [17]. Filipa et al. found to have a significant effect star excursion balance test young women athletes neuromuscular strength training program [12]. General strength trainings increases body mass reduces risk of injury and contributes to the development of core stability [34]. In particular, where the players active branches leading to effective results application of functional training to the core region. Strengthening muscle groups that are effective on balance is important since balance will provide technical advantage to athlete.

As a result, it has been found that both methods contribute to the balance in this study where the balance scores are evaluated in the traditional bar and bandbell Earthquake bar strength training practices. Bandbell earthquake bar strength training practice should consider the upper limit of resistance of the bamboo bar.

\section{References}

1. Anderson, C. E., Sforzo, G. A., Sigg, J. A. The effects of combining elastic and free weight resistance on strength and power in athletes. Journal of Strength and Conditioning Research, 22, 2, 567-574 (2008)

2. Ashton-Miller JA, Wojtys EM, Huston LJ, et al. Can proprioception really be improved by exercises? Knee Surg Sports Traumatol Arthrosc (2001)

3. Arazi H, Coetzee B, Asadi A Comparative effect of land and aquatic based plyometric training on the jumping ability and agility of young basketball players. S Afr J Res Sport Phys Edu Rec 34, 1-1, (2012)

4. Azar, J. A. Effects of Unstable Versus Stable Free Weights on Surface EMG of Shoulder Musculature in Males (Doctoral dissertation, Ohio University (2016)

5. http://www.fitnessshop.com.tr/urunler/fonksiyonel-egzersiz-ekipmanlari/bandbellearthquake-bar/\#aciklama) Access date:14.06.2017

6. http://www.ardsport.com/?uid=176_Access date:14.06.2017

7. D. G., Anderson, K. G. (2006). The role of instability with resistance training. Journal of Strength and Conditioning Research, 20, 3, 716-722.

8. Behm, D. G., Leonard, A. M., Young, W. B., Bonsey, A. C., \& MacKinnon, S. N. Trunk muscle electromyographic activity with unstable and unilateral exercises. Journal of Strength and Conditioning, 19, 1, 193-201, (2005)

9. Boyle, M. Advances in functional training: training techniques for coaches, personal trainers and athletes. On Target Publications. (2012)

10. Dasteridis, Giorgos., Piliandis, T., Mantzouranis, Nikos. The effect of different strength training programmes on young athletes' sprint performance. Stud Phys Cult Tourism, 18, 2, 141-147 (2011)

11. Dunnick, D. D., Brown, L. E., Coburn, J. W., Lynn, S. K., Barillas, S. R. Bench press upper-body muscle activation between stable and unstable loads. Journal of Strength and Conditioning Research, 29, 12, 3279-3283 (2015)

12. Filipa, A., Byrnes, R., Paterno, M. V., Myer, G. D., Hewett, T. E. Neuromuscular training improves performance on the star excursion balance test in young female athletes. Journal of orthopaedic \& sports physical therapy, 40, 9, 551-558 (2010)

13. Hewett Te, Stroupe Al, Nance Ta, Noyes Fr. Plyometric training in female athletes. American Journal of Sports Medicine, 24, 765-773 (1996)

14. Hess, J. A., Woollacott, M. Effect of high-intensity strength-training on functional measures of balance ability in balance-impaired older adults. Journal of manipulative and physiological therapeutics, 28, 8, 582-590, (2005) 
15. Kellis, E., Arabatzi, F., Papadopoulos, C. Muscle co-activation around the knee in drop jumping using the co-contraction index. Journal of Electromyography and Kinesiology, 13, 3, 229-238 (2003)

16. Klinzing, J.E. Training for improved jumping ability of basketball players. Nat Strength Cond Asso J, 13, 27-32 (1991)

17. Lee, I. H., Park, S. Y. Balance improvement by strength training for the elderly. Journal of physical therapy science, 25, 12, 1591-1593 (2013)

18. Lehnert, M., Hůlka, K., Malý, T., Fohler, J., Zahálka, F. The effects of a 6 week plyometric training programme on explosive strength and agility in professional basketball players. Acta Gymnica, 43, 4, 7-15 (2013)

19. Mahmoud H. Mahmoud Balance Exercises as the Basis for Developing the Level of Physical and Skill Performance in Basketball Young Players .World Journal of Sport Sciences 4, 2 172-178 (2011)

20. McBride, J. M., Larkin, T. R., Dayne, A. M., Haines, T. L., Kirby, T. J. Effect of absolute and relative loading on muscle activity during stable and unstable squatting. International Journal of Sports Physiology and Performance, 5, 2, 177- 183 (2010)

21. Muehlbauer, T., Gollhofer, A., Granacher, U. Association of balance, strength, and power measures in young adults. The Journal of Strength \& Conditioning Research, 27, 3, 582-589 (2013)

22. Myklebust G, Engebretsen L, Braekken Ih, Skjolberg A, Olsen Oe, Bahr R. (2003) Prevention of anterior cruciate ligament injuries in female team handball players: A prospective intervention study over three seasons. Clinical Journal of Sports Medicine. 13:71-78.

23. Nairn, B. C., Sutherland, C. A., Drake, J. D. M. Location of instability during a bench press alters movement patterns and electromyographical activity. Journal of Strength and Conditioning Research, 29, 11, 3162-3170 (2015)

24. Ostrowski, S, Carlson, LA, and Lawrence, MA. Effect of an unstable load on primary and stabilizing muscles during the bench press. J Strength Cond Res 31, 430-434 (2017)

25. Park, S. Y., \& Yoo, W. G. Differential activation of parts of the serratus anterior muscle during push-up variations on stable and unstable bases of support. Journal of Electromyography Kinesiology, 21, 5, 861-867 (2011)

26. Paterno mv.myer g. Jun.Neuro muscular training improves single-limb stability in young female athletes. J Orthop Sports Phys Ther, 34, 6, 305-16 (2004)

27. Pinto, R., Cadore, E., Correa, C., Gonçalves Cordeiro da Silva, B., Alberton, C., Lima, C., \& de Moraes, A. Relationship between workload and neuromuscular activity in the bench press exercise. Medicina Sportiva, 17, 1, 1-6. (2013)

28. Randa, et al. Effect of physical activity and sporting activities on balance control in elderly people.British journal of sportsmedicine, 33, 2 (2001)

29. Soria-Gila, M. A., Chirosa, I. J., Bautista, I. J., Baena, S., \& Chirosa, L. J. Effectsof variable resistance training on maximal strength: A meta-analysis. Journal of Strength and Conditioning Research, 29, 11, 3260-3270 (2015)

30. Tchórzewski, D., Bujas, P., Jankowicz-Szymańska, A. Body posture stability in ski boots under conditions of unstable supporting surface. Journal of human kinetics, 38, 33-44 (2013)

31. Tchórzewski, D., Jaworski, J., Bujas, P. Influence of long-lasting balancing on unstable surface on changes in balance. Human Movement, 11, 2, 144-152 (2010)

32. Thompson, C. J., Cobb, K. M., Blackwell, J. Functional training improves club head speed and functional fitness in older golfers. The Journal of Strength \& Conditioning Research, 21, 1, 131-137 (2007) 
33. Young, M.D.,Jordan D. Metzl, MAY. Strength Training for the Young Athlete Warren K. Mdpediatric Annals 39, 5 (2010)

34. Young, W. B. Transfer of strength and power training to sports performance. International journal of sports physiology and performance, 1, 2, 74 (2006) 